\title{
Propriedades energéticas do carvão vegetal em função do espaçamento de plantio
}

\author{
Maria Fernanda Vieira Rocha ${ }^{1^{*}}$, Benedito Rocha Vital ${ }^{2}$, Angélica de Cássia Oliveira Carneiro ${ }^{2}$, Ana \\ Márcia Macêdo Ladeira Carvalho², Antônio José Vinha Zanuncio ${ }^{3}$, Paulo Ricardo Gherardi Hein ${ }^{1}$ \\ ${ }^{1}$ Programa de Pós-Graduação em Ciência e Tecnologia da Madeira, Universidade Federal de Lavras, Lavras - Brasil. \\ ${ }^{2}$ Departamento de Engenharia Florestal, Universidade Federal de Viçosa, Viçosa - Brasil. \\ ${ }^{3}$ Departamento de Engenharia Florestal, Universidade Federal de Uberlândia, Monte Carmelo - Brasil.
}

\begin{abstract}
RESUMO O objetivo do estudo foi verificar a influência do espaçamento no plantio de um híbrido de Eucalyptus grandis $\mathrm{x}$ Eucalyptus camaldulensis no rendimento gravimétrico e nas propriedades do carvão vegetal. Para tanto, foram realizadas determinação da composição química, na densidade e no poder calorífico do carvão. Valores de massa seca, massa de carbono, teor de lignina, rendimento em carvão vegetal e energia disponível em função do espaçamento também foram analisados. Foram avaliados cinco espaçamentos: $3,0 \times 0,5 ; 3,0 \times 1,0 ; 3,0 \times 1,5 ; 3,0 \times 2,0$ e 3,0 x 3,0 metros, e de cada espaçamento foram selecionadas três árvores, caracterizando três repetições. Retirou-se discos das árvores a $0 \%, 25 \%, 50 \%, 75 \%$ e $100 \%$ da altura comercial do tronco. Para cada árvore analisada, a carbonização foi realizada a partir de uma amostra composta obtida por amostras dos discos. Os resultados encontrados mostram que para massa seca, massa de carbono, massa de lignina, massa de energia estocada por hectare/ano, no rendimento gravimétrico e nas propriedades do carvão vegetal o melhor espaçamento foi o de 3,0 x 1,5 metros, tendo em vista o plantio de árvores objetivando a produção de carvão vegetal.
\end{abstract}

Palavras-chave: energia, plantios adensados, biomassa.

\section{Energetic properties of charcoal as a function of plant spacing}

\begin{abstract}
The objective of the study was to verify the influence of plant spacing on a hybrid of Eucalyptus grandis $\mathrm{x}$ Eucalyptus camaldulensis on the gravimetric yield and charcoal properties. The determination of the chemical composition, density and the calorific value of the charcoal were carried out. Values of dry mass, carbon mass, lignin content, charcoal yield and available energy as a function of spacing were also analyzed. Five spacings were evaluated: $3.0 \times 0.5 ; 3.0 \times 1.0 ; 3.0 \times 1.5 ; 3.0 \times 2.0$ and $3.0 \times 3.0$ meters, and from each plant spacing were selected three trees, characterizing three replicates. Discs were removed from the trees at $0 \%, 25 \%, 50 \%, 75 \%$ and $100 \%$ of the commercial height of the trunk. For each tree analyzed, the carbonization was performed from a composite sample obtained by samples of the discs. The results show that for dry mass, carbon mass, lignin mass, energy mass stored per hectare / year, gravimetric yield and charcoal properties, the best spacing was $3.0 \times 1.5$ meters, in order to plant trees for the production of charcoal.
\end{abstract}

Keywords: energy, densified plantings, biomass.

\section{Introdução}

A madeira exerce um importante papel como um material ambientalmente sustentável e um recurso renovável. Os desmatamentos das florestas naturais que ocorrem no Brasil ocasionam problemas econômicos e ambientais, desta forma, com o estabelecimento de plantações florestais visando fornecer matéria-prima

para suprir a demanda industrial pode-se reduzir, ou até mesmo cessar com o desmatamento de florestas naturais, garantindo assim uma padronização e maior qualidade do carvão vegetal utilizado em siderurgias.

O Produto Interno Bruto (PIB) Florestal corresponde a cerca de $1,1 \%$ do PIB nacional e 5,5\% do PIB 
industrial, o que mostra a importância do setor na economia nacional. Além disso, o setor tem garantido a produção de produtos tanto para o consumo direto ou para exportação e contribuindo para geração de empregos e também para a conservação dos recursos naturais (IBÁ, 2015).

Um dos grandes problemas industriais existentes hoje, principalmente no setor siderúrgico, é a heterogeneidade do carvão vegetal utilizado nos altos fornos. As variações na qualidade do carvão são atribuídas às condições e fatores de todo o processo de carbonização, além da qualidade da madeira utilizada (SOARES et al., 2015). As variações nas propriedades da madeira estão relacionadas ao material genético, idade, tratamentos silviculturais, entre outros, uma vez que esses fatores causam alterações fisiológicas no material, podendo acarretar alteração na qualidade do carvão vegetal produzido (LATORRACA; ALBUQUERQUE, 2000). De acordo com Nones et al. (2015), quando se planeja e se executa um manejo adequado dos reflorestamentos de Eucalyptus, é possível obter árvores com madeira de propriedades mais adaptadas para obtenção de um carvão vegetal adequada a aplicação em siderurgia.

O espaçamento de plantio é um dos tratamentos silviculturais de maior importância quando se visa a instalação de um plantio florestal, uma vez que o mesmo tem influência direta no crescimento das árvores, na qualidade da madeira, idade de corte e nos aspectos econômicos de todo investimento (MAGALHÃES et al., 2007). Segundo Trugilho et al. (2001), a qualidade e a quantidade do carvão vegetal produzidos sofrem in- fluência direta da matéria prima utilizada para a produção do mesmo, ou seja, uma madeira com melhores propriedades como alta densidade básica, irá produzir um carvão também de alta densidade. Neves et al. (2011) afirmaram que o incremento volumétrico da árvore também pode influenciar significativamente na produção e na qualidade do carvão, uma vez que o mesmo está diretamente relacionado ao processo de formação e crescimento da madeira e afeta diretamente a quantidade de massa seca produzida por indivíduo.

Nesse contexto, neste trabalho objetivou-se verificar a influência do espaçamento de plantio no rendimento e na qualidade do carvão vegetal da madeira de Eucalyptus.

\section{Material e Métodos}

\section{Material vegetal e tratamentos}

Foram utilizados clones de Eucalyptus (híbrido de Eucalyptus grandis Hill ex Maiden x Eucalyptus camaldulensis Dehnh.) com sete anos de idade, fornecidos pela empresa ArcelorMittal Jequitinhonha, localizada em Minas Gerais, no município de Itamarandiba, com coordenadas geográficas $17,86^{\circ} \mathrm{S}$ de latitude e $42,86^{\circ} \mathrm{W}$ de longitude, norte do estado de Minas Gerais.

O experimento foi instalado em dezembro de $2002 \mathrm{em} \mathrm{um}$ delineamento em blocos casualizados. As árvores foram selecionadas tendo em vista os cinco espaçamentos de plantio. Os espaçamentos de plantio utilizados foram: 3 x 0,5 m; 3 x 1 $\mathrm{m} ; 3 \times 1,5 \mathrm{~m} ; 3 \times 2 \mathrm{~m}$ e $3 \times 3 \mathrm{~m}$. Para cada tratamento foram utilizadas três árvores, o que caracterizou-se como as repetições. 
Para o preparo das amostras, discos de 6,0 $\mathrm{cm}$ de espessura foram retirados a $0 \%, 25 \%, 50 \%, 75 \%$ e $100 \%$ da altura comercial do tronco de cada árvore.

A carbonização da madeira foi realizada a partir de uma amostra composta por árvore, que foi obtida através de parte dos discos retirados nas diversas alturas das mesmas. As carbonizações foram realizadas em forno do tipo mufla de laboratório com aquecimento elétrico, utilizando-se cerca de $350 \mathrm{~g}$ de madeira, as quais foram inseridas em um recipiente metálico com dimensões de $30 \mathrm{~cm}$ de comprimento e $12 \mathrm{~cm}$ de diâmetro. A recuperação dos gases condensáveis foi feita por meio de um condensador tubular adaptado à porta da mufla. O tempo total de carbonização da madeira foi de 3,5 horas, com temperatura inicial de $150^{\circ} \mathrm{C}$ e final de $450^{\circ} \mathrm{C}$ e com taxa de aquecimento média de $1,67{ }^{\circ} \mathrm{C} \mathrm{min}^{-1}$. Posteriormente à carbonização, foram determinados os rendimentos gravimétricos em carvão, em gases condensáveis e em gases não-condensáveis. O rendimento gravimétrico em carbono fixo foi obtido multiplicando-se o rendimento gravimétrico em carvão vegetal pelo teor de carbono fixo (TRUGILHO et al., 2005).

A determinação da densidade aparente do carvão vegetal foi realizada com base na norma NBR 11941 (ABNT, 2003). A análise imediata, para determinação dos teores de materiais voláteis (TMV), cinza (TCZ) e, por diferença, o teor de carbono fixo (TCF), foi realizada de acordo com a norma NBR 8112 (ABNT, 1986). O poder calorífico superior do carvão foi determinado por meio da bomba calorimétrica adiabática, segundo a norma NBR 8633 (ABNT, 1983).

A massa seca de madeira sem casca por hectare/ ano foi obtida multiplicando-se o incremento médio anual $\left(\mathrm{m}^{3} / \mathrm{ha} . \mathrm{ano}\right)$ da madeira sem casca pela densidade básica da madeira $\left(\mathrm{kg} \cdot \mathrm{m}^{-3}\right)$, conforme a equação (1):

$$
\text { MSM }=\text { IMA X Dbm }
$$

em que: $\mathrm{MSM}=$ massa seca de madeira $\left(\mathrm{t} \cdot \mathrm{ha}^{-1} \cdot \mathrm{ano}^{-1}\right) ; \mathrm{IMA}=$ incremento médio anual $\left(\mathrm{m}^{3} \cdot \mathrm{ha}^{-1} \cdot \mathrm{ano}^{-1}\right)$; e Dbm $=$ densidade básica da madeira $\left(\mathrm{kg} \cdot \mathrm{m}^{-3}\right)$.

A massa de carbono (expressa em tonelada) foi obtida multiplicando-se a massa seca de madeira pela porcentagem de carbono na madeira, conforme a Equação 2:

$$
\mathrm{MC}=\mathrm{MSM} \times \mathrm{C}
$$

em que: $\mathrm{MC}=$ massa de carbono $\left(\mathrm{t} \cdot \mathrm{ha}^{-1} \cdot \mathrm{ano}^{-1}\right) ; \mathrm{Msm}=\mathrm{MSM}$ = massa seca da madeira $\left(\mathrm{t} \cdot \mathrm{ha}^{-1} \cdot \mathrm{ano}^{-1}\right) ; \mathrm{e} \mathrm{C}(\%)=$ porcentagem de carbono/100.

As massas de lignina e de carvão vegetal, expressas em tonelada, foram determinadas multiplicando-se a massa seca de madeira pelo percentual de lignina total e rendimento gravimétrico em carvão vegetal, respectivamente, conforme as seguintes Equações 3 e 4:

$$
\text { ML (ton) }=\text { Msm x LT }
$$

em que $M L=$ massa de lignina $;$ Msm = massa seca da madeira (t) e LT = lignina total/100.

$$
\mathrm{MCV}(\text { ton })=\mathrm{Msm} \times \mathrm{RCV}
$$

em que $\mathrm{MCV}=$ massa de carvão vegetal; $\mathrm{Msm}=$ massa seca da madeira e RGCV = rendimento gravimétrico em carvão vegetal/100.

Para o cálculo da quantidade de energia por hectare/ano, expressa em kW.h, multiplicou-se a massa seca da madeira (t) pelo poder calorífico superior, calculado pela Equação 5:

$$
\text { Energia/ha }(\text { KW.h })=\text { Msm x PCS mad }
$$


em que: energia $(\mathrm{kW} . \mathrm{h})$ = energia por hectare; Msm = massa seca da madeira $\left(\right.$ t. ha ${ }^{-1}$.ano $\left.{ }^{-1}\right)$ e PCS mad $=$ poder calorífico superior da madeira $\left(\mathrm{kcal}_{\mathrm{kg}} \mathrm{kg}^{-1}\right)$.

Os dados dos parâmetros avaliados foram submetidos à análise de variância (ANOVA), aplicando-se o teste F, e posteriormente as médias foram comparadas pelo teste de Tukey.

\section{Resultados e Discussão}

\section{Rendimentos de carbonização}

Observa-se que para os valores de rendimento gravimétrico do carvão, dos gases condensáveis e gases não condensáveis e carbono fixo, não houve efeito dos espaçamentos de plantio (Figura 1).

Os valores médios encontrados para o rendimento gravimétrico do carvão vegetal neste estudo variaram entre $28,01 \%$ e $30,8 \%$, para o rendimento dos gases condensáveis de $31,13 \%$ a $34,82 \%$, para o rendimento dos gases não condensáveis de
$36,20 \%$ a $39,64 \%$, e para o carbono fixo de $20,79 \%$ a $22,22 \%$.

Resultados similares foram reportados anteriormente para o RGC e RGNC (NEVES et al., 2011).

Valores elevados de rendimento gravimétrico em carvão vegetal são desejáveis no processo de produção devido ao maior aproveitamento da madeira nos fornos de carbonização e, consequentemente, da maior produção de energia e dos menores rendimentos em líquido e em gases não condensáveis, pois estes são subprodutos do processo de pirólise (PROTÁSIO et al., 2011).

Altos valores em rendimento em carbono fixo são desejáveis quando se pretende indicar materiais genéticos para produção de carvão vegetal, uma vez que o rendimento em carbono fixo envolve, simultaneamente, características de produtividade e de qualidade relacionadas ao carvão vegetal (TRUGILHO et al., 1997). O carbono fixo pode ser definido como a quantidade de carbono presente no carvão vegetal, desta forma o rendimento em carbono fixo apresenta uma

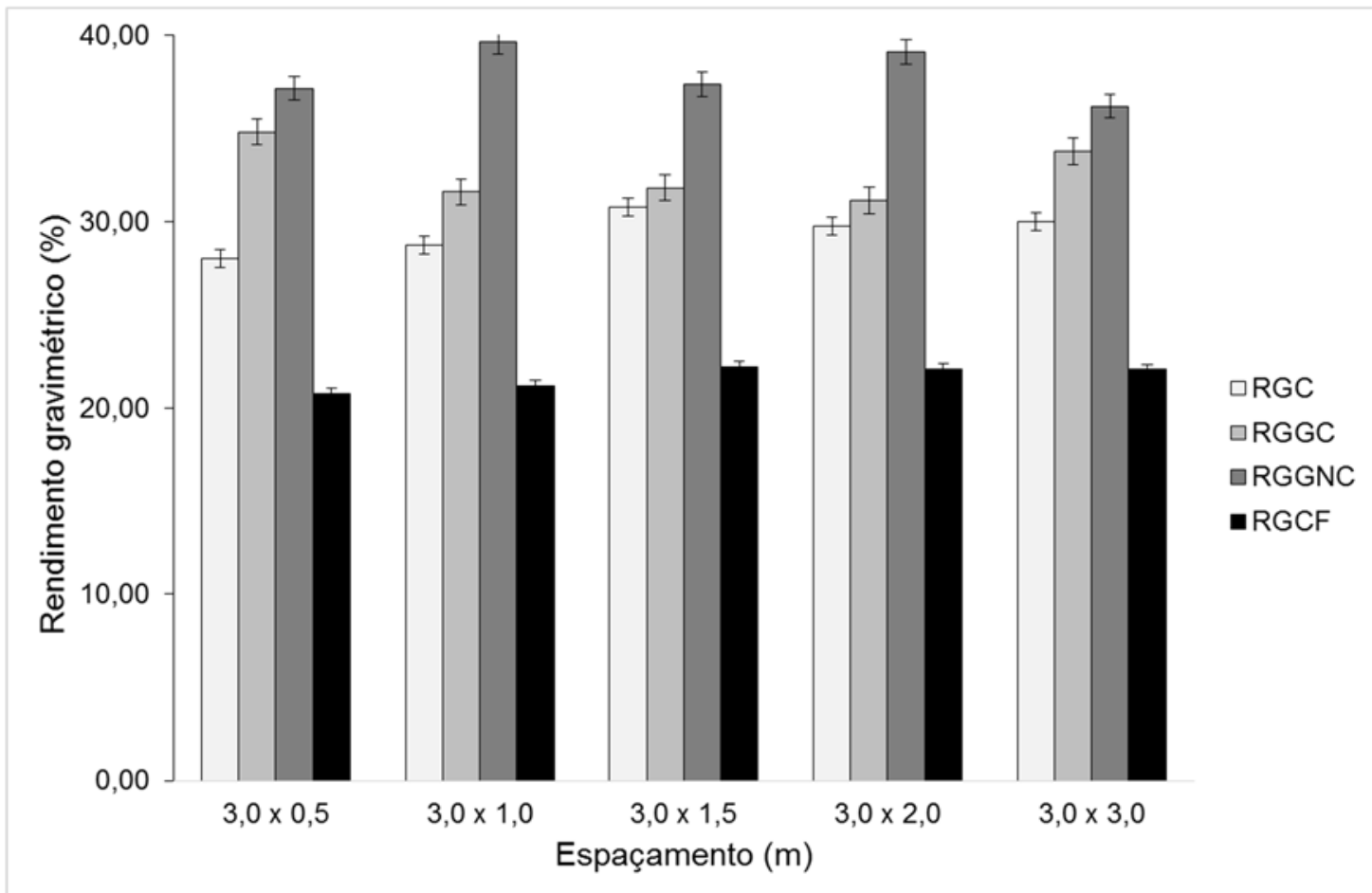

Figura 1. Rendimento gravimétrico do carvão vegetal (RGC), dos gases condensáveis (RGGC), dos gases não condensáveis (RGGNC) e em carbono fixo (RGCF) por espaçamento. Médias não diferem entre si, a 5\% de significância, pelo teste Tukey. Figure 1. Charcoal gravimetric (RGC), condensable gases (RGGC), non-condensable gases (RGGNC) and fixed carbon (RGCF) by spacing. Means do not differ among them at $5 \%$ of significance by the Tukey test. 
relação direta e proporcional aos teores de lignina, extrativos e massa específica ou densidade básica da madeira (LIMA et al., 2007).

As médias do rendimento gravimétrico do carvão e rendimento gravimétrico dos gases condensáveis e não condensáveis e carbono fixo neste estudo não diferiram entre os diferentes espaçamentos de plantio, e os resultados encontrados estão coerentes com aqueles encontrados por Reis et al. (2012), Botrel et al. (2007), Trugilho et al.(2001) e por Brito et al. (1984).

\section{Caracterização física}

Observa-se que não houve diferença estatística significativa entre os valores da densidade aparente média para a madeira amostrada nos diferentes espaçamentos (Figura 2), onde de acordo com Ferreira (1997), a quantidade de madeira estocada em um determinado sítio tende a se igualar em diferentes espaçamentos depois de uma certa idade das árvores. Árvores plantadas em espaçamentos mais adensados tem uma estagnação do seu crescimento em idades mais jovens, já aquelas plantadas em espaçamentos mais amplos, a estagnação do crescimento ocorre em idades mais avançadas (LEITE et al., 2006). Como a densidade aparente do carvão vegetal sofre influência direta dos valores da densidade básica da madeira, a relação do incremento da densidade com a taxa de crescimento pode ser aplicada. Os valores finais da densidade aparente do carvão vegetal são relativamente inferiores aos valores da densidade básica da madeira, isso ocorre devido ao processo de carbonização onde ocorre a degradação térmica dos constituintes da madeira (SYRED et al., 2006).

Do ponto de vista econômico, essa relação do incremento em madeira em função de diferentes espaçamentos de plantio com a densidade da madeira e do carvão tem grande impor-

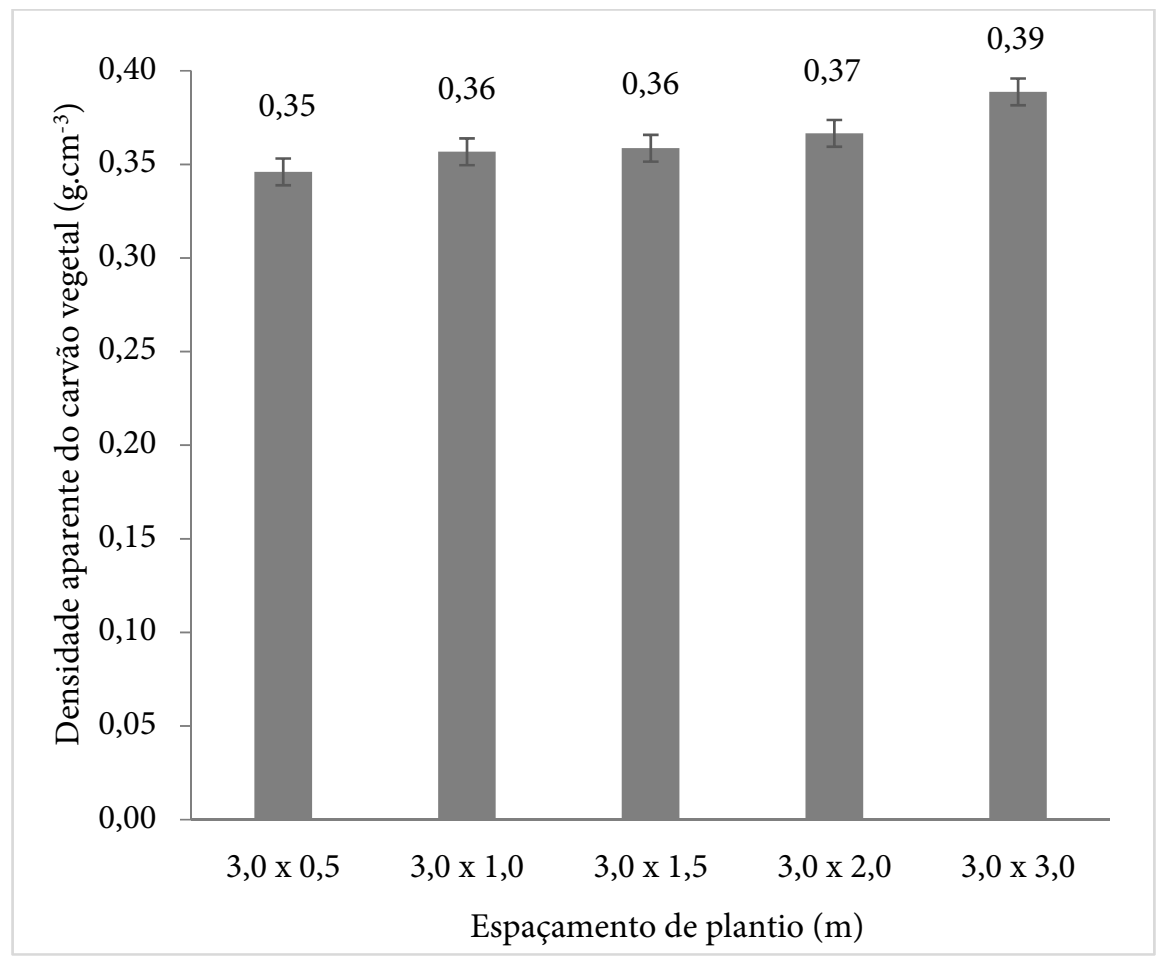

Figura 2. Densidade aparente média do carvão vegetal por espaçamento. Médias não diferem entre si, a $5 \%$ de significância, pelo teste Tukey.

Figure 2. Average bulk density of the charcoal by plant spacing. Means do not differ among them at $5 \%$ of significance by the Tukey test. 
tância, uma vez que pode-se economizar no custo de implantação, na colheita e transporte de madeira. Considerando um maior espaçamento entre as árvores, obtém-se maior dimensão das mesmas e um menor volume total, o que irá diminuir os custos de manutenção e colheita da floresta e transporte da madeira. Entretanto, como a madeira terá maior diâmetro, demandará um maior tempo para secagem em pátio e provavelmente será carbonizada com maior umidade, prejudicando todo processo de carbonização e consequentemente influenciando na qualidade final do carvão vegetal produzido.

Os valores da densidade aparente média do carvão vegetal encontrados nesse trabalho variam de 0,35 a $0,39 \mathrm{~g} \mathrm{~cm}^{-3}$. Trabalhando com três clones e híbridos de Eucalyptus, Neves et al. (2011) e Trugilho et al. (2005) encontraram valores semelhantes de densidade média de carvão vegetal.

De acordo com Vital (1986), quando se visa a produção de carvão vegetal, a utilização de madeira de maior densidade básica resulta em um carvão com maior densidade aparente e maior rendimento gravimétrico em carvão vegetal por unidade de forno. Isto foi observado por Trugilho et al. (2001), onde trabalhando com clones de Eucalyptus aos sete anos de idade, concluíram que aqueles que apresentaram densidade básica da madeira variando de 0,52 a $0,59 \mathrm{~g} \mathrm{~cm}^{-3}$ produziram um carvão com melhores características para o setor siderúrgico, como menor friabilidade, maior poder calorífico, maior teor de carbono fixo, menor teor de cinzas e voláteis, entre outros.

\section{Análise química imediata do carvão}

Para os valores encontrados para a análise imediata do carvão vegetal nos cinco espaçamentos analisados não foram observados efeitos dos espaçamentos de plantio (Figura 3). De maneira geral, a partir da análise imediata do carvão obtido dos diferentes espaçamentos, os teores carbono fixo ob- servados variaram entre $72,16 \%$ e $74,22 \%$, os teores de materiais voláteis entre $25,44 \%$ e $27,56 \%$ e os teores de cinzas entre $0,28 \%$ e $0,39 \%$. Esses valores foram semelhantes aos encontrados por Botrel et al. (2007), que avaliou a composição química imediata do carvão de clones de Eucalyptus ssp. aos 78 meses de idade e encontrou, para o carbono fixo, valores entre $71,74 \%$ e $76,93 \%$, para materiais voláteis, valores entre $22,86 \%$ e $27,98 \%$ e para cinzas, valores entre $0,16 \%$ e $0,34 \%$.

Para os valores de cinzas o limite máximo de 1,5\% determinado pela norma PMQ 3-03 (SÃO PAULO, 2003) é utilizado como base de forma a não comprometer o uso siderúrgico do biocombustível. Diversos trabalhos na literatura encontraram teores de cinzas inferiores a $1 \%$ para o carvão vegetal de vários clones e espécies de Eucalyptus (TRUGILHO et al., 2005; BOTREL et al., 2007; OLIVEIRA et al., 2010; NEVES et al., 2011), corroborando com o observado neste trabalho.

O teor carbono fixo tem relação direta com o poder calorífico. Um maior teor de carbono fixo implica em um maior tempo de residência dentro do aparelho de queima. Já as cinzas são substâncias compostas de material inorgânico e tem relação inversa com o poder calorífico. Os materiais voláteis durante a queima da biomassa volatilizam rapidamente diminuindo o tempo de residência do combustível dentro do aparelho de combustão, podendo contribuir para uma baixa eficiência energética. O teor de carbono fixo depende principalmente do teor de material volátil, já que os teores de cinzas para madeira de Eucalyptus são baixos. Desta forma, madeira com maiores teores de material volátil tem menores teores de carbono fixo (CHAVES et al., 2013).

\section{Caracterização energética da biomassa}

Não foram observados efeitos significativos do espaçamento de plantio nos valores do poder calorífico superior do carvão vegetal, sendo que os valores situaram-se na faixa de 


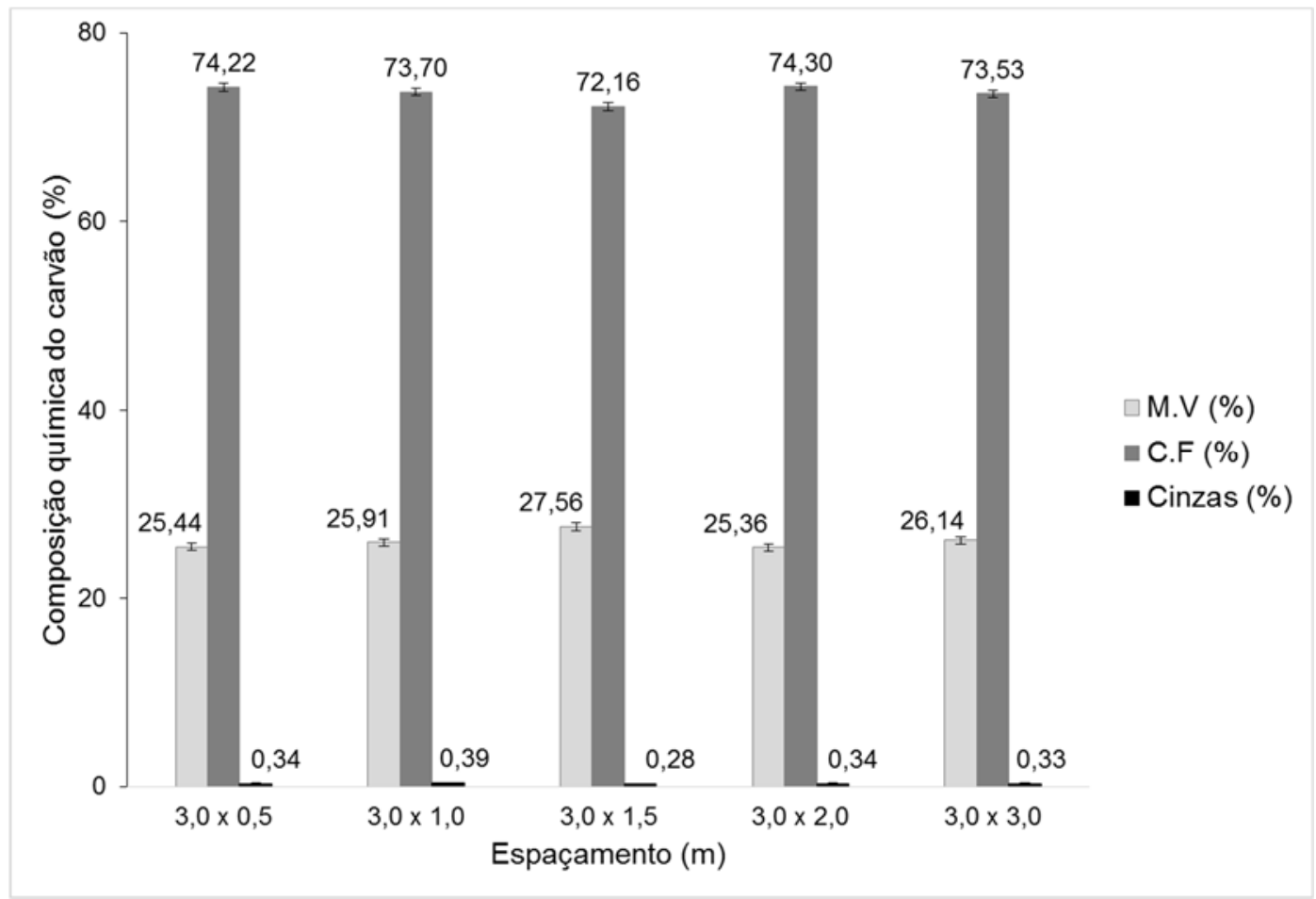

Figura 3. Análise química imediata do carvão vegetal (A) e Teor de cinzas (B) por espaçamento. Médias não diferem entre si, a $5 \%$ de significância, pelo teste Tukey.

Figure 3. Proximate chemical analysis of charcoal (A) and ash content (B) by spacing. Means do not differ among them at $5 \%$ of significance by the Tukey test.

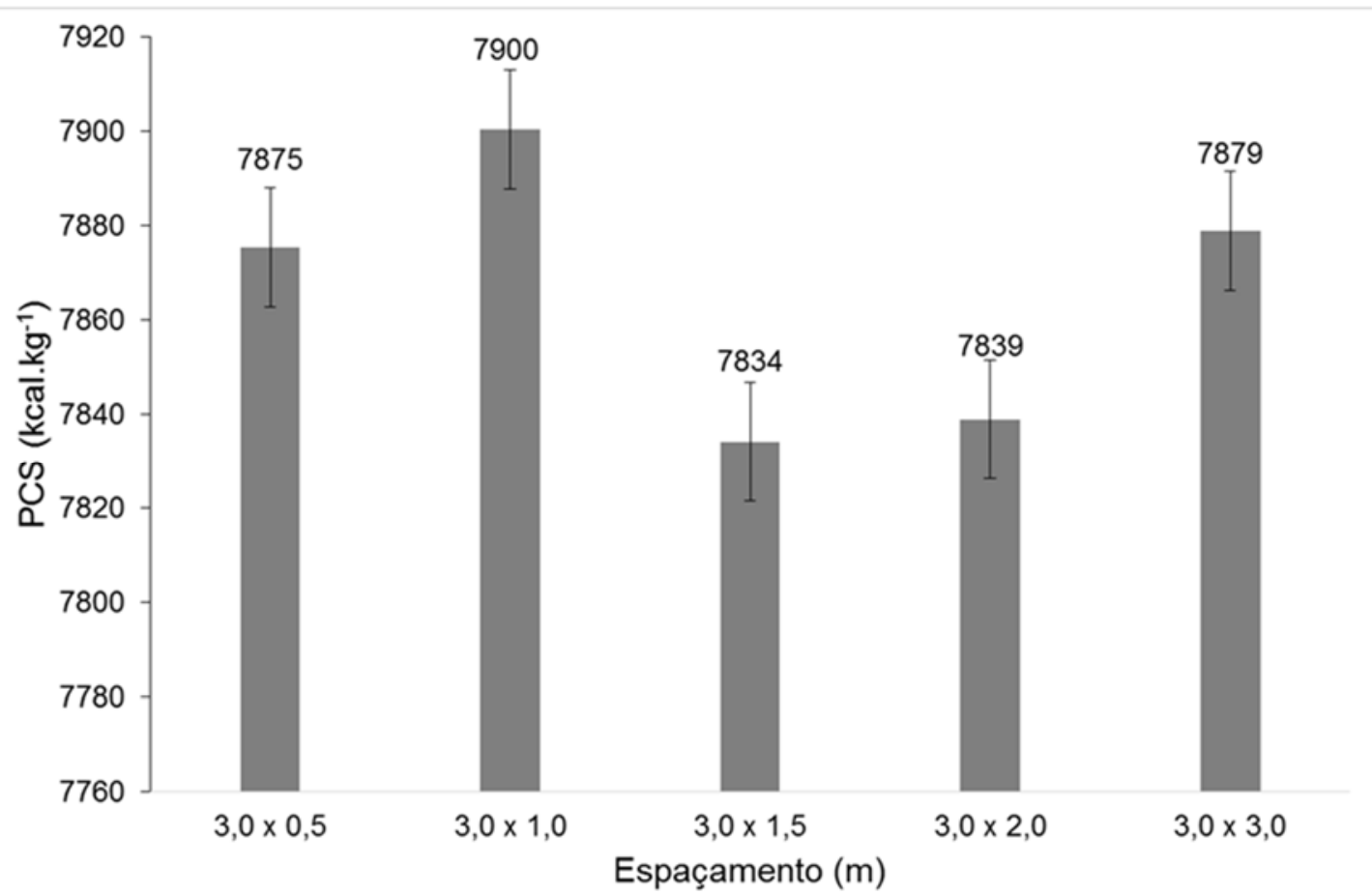

Figura 4. Poder calorífico superior do carvão vegetal por espaçamento. Médias não diferem entre si, a 5\% de significância, pelo teste Tukey.

Figure 4. High heating value of charcoal by spacing. Means do not differ among them at $5 \%$ of significance by the Tukey test. 
7.834 a $7900 \mathrm{kcal} \mathrm{kg}^{-1}$, respectivamente (Figura 4). Reis et al. (2012) obtiveram valores para o poder calorífico superior médio igual a $7086 \mathrm{kcal} \mathrm{kg}^{-1}$ para um clone de Eucalyptus urophylla. Valores semelhantes de PCS para diferentes espécies de Eucalyptus foram obtidos por Chaves et al. (2013) de $7575 \mathrm{kcal} \mathrm{kg}^{-1}$, Santos (2008) de $7500 \mathrm{kcal} \mathrm{kg} 1$, Vale et al. (2002) de $7591 \mathrm{kcal} \mathrm{kg}^{-1}$, Vella et al. (1989) de $7787 \mathrm{kcal} \mathrm{kg}^{-1}$, entre outros.

Desta forma, observa-se que os valores encontrados neste estudo estão dentro do esperado para clones de Eucalyptus, sendo assim, os carvões produzidos a partir do material genético em questão apresentam valores satisfatórios de PCS, considerando todos os espaçamentos de plantio utilizados, uma vez que não houve diferença estatística significativa entre eles. Um carvão vegetal que possui um maior poder calorífico superior, principalmente quando se visa o emprego siderúrgico do mesmo, contribui para um menor consumo de insumo termo redutor, considerando uma mesma produtividade. Outros fatores podem ser analisados quando se tem um carvão vegetal visando a produção de energia, como estimativa da massa seca, massa de lignina, massa de carvão, massa de carbono na madeira e energia por hectare, que estão apresentados na Tabela 1.

Quanto à massa seca por hectare/ano, pode-se observar que o maior valor foi observado no espaçamento 3,0 x 1,5 me- tros. Este resultado pode estar relacionado aos valores da densidade básica da madeira. Os valores deste estudo estão dentro da margem de valores encontrados por Santos et al. (2012), que, analisando clones de Eucalyptus plantados em diferentes locais obteve no espaçamento uma produção de massa de matéria seca de madeira variando de 15,25 a 23,28 t/ha.ano.

Quando se visa a utilização de madeira para fins energéticos, fica evidente a importância da produtividade volumétrica e da densidade básica, uma vez que esses dois parâmetros determinam a produção de massa seca de madeira (ROCHA et al.,2015). Assim, para a produção de energia, através da queima direta ou produção de carvão vegetal, a quantificação de massa de madeira é mais importante do que a utilização dos parâmetros dendrométricos, como o diâmetro, a altura e o volume de madeira (OLIVEIRA et al., 1991).

A maior massa de carbono foi observada no espaçamento 3,0 x 1,5 metros, que diferiu estatisticamente dos espaçamentos $3,0 \times 0,5 ; 3,0 \times 2,0$ e 3,0 × 3,0 metros. Esses valores foram obtidos considerando os valores médios de porcentagem de carbono na madeira e os valores médios das estimativas de massa de matéria seca. As árvores plantadas nos espaçamentos que apresentaram maiores valores de massa seca de madeira também exibiram maiores massas de carbono, assim como aqueles que tiveram menores valores de massa de maté-

Tabela 1. Valores de massa seca, massa de carbono, massa de lignina, massa de carvão vegetal e energia disponível em função do espaçamento.

Table 1. Values of dry mass, carbon mass, mass lignin, charcoal mass and energy available due to the by spacing.

\begin{tabular}{lccccc}
\hline $\begin{array}{l}\text { Espaçamento de } \\
\text { plantio (m) }\end{array}$ & $\begin{array}{c}\text { Massa seca } \\
\text { (ton/ha.ano) }\end{array}$ & $\begin{array}{c}\text { Massa de carbono } \\
\text { (ton/ha.ano) }\end{array}$ & $\begin{array}{c}\text { Energia (KW.h/ha. } \\
\text { ano) }\end{array}$ & $\begin{array}{c}\text { Massa de lignina } \\
\text { (ton/ha. ano) }\end{array}$ & $\begin{array}{c}\text { Massa de carvão } \\
\text { vegetal } \\
\text { (ton/ha.ano) }\end{array}$ \\
\hline $3,0 \times 0,5$ & $18,27^{\mathrm{bc}}$ & $9,14^{\mathrm{bc}}$ & $80799^{\mathrm{ab}}$ & $5,65^{\mathrm{b}}$ & $5,11^{\mathrm{b}}$ \\
$3,0 \times 1,0$ & $19,44^{\mathrm{ab}}$ & $9,73^{\mathrm{ab}}$ & $85406^{\mathrm{a}}$ & $5,71^{\mathrm{b}}$ & $5,59^{\mathrm{ab}}$ \\
$3,0 \times 1,5$ & $20,02^{\mathrm{a}}$ & $10,01^{\mathrm{a}}$ & $86815^{\mathrm{a}}$ & $6,36^{\mathrm{a}}$ & $6,16^{\mathrm{a}}$ \\
$3,0 \times 2,0$ & $18,64^{\mathrm{b}}$ & $9,32^{\mathrm{b}}$ & $81592^{\mathrm{ab}}$ & $6,12^{\mathrm{ab}}$ & $5,54^{\mathrm{a}}$ \\
$3,0 \times 3,0$ & $17,23^{\mathrm{c}}$ & $8,61^{\mathrm{c}}$ & $76223^{\mathrm{b}}$ & $5,66^{\mathrm{b}}$ & $5,17^{\mathrm{a}}$ \\
\hline
\end{tabular}

Médias seguidas da mesma letra não diferem entre si, a 5\% de significância, pelo teste Tukey. Means followed by the same letter do not differ from each other, at $5 \%$ of significance, by the Tukey test. 
ria seca apresentaram também menores massas de carbono.

Neste caso, os valores encontrados para massa de carbono foram semelhantes aos encontrados por Santos et al. (2012), que obteve massa de carbono dentro da variação de 7,18 a 10,66 t/ha.ano.

Quanto à massa de carvão vegetal estimada por hectare/ano, pode-se observar que o espaçamento que apresentou resultados mais satisfatórios foi o 3,0 x 1,5 metros, o que está relacionado à maior massa seca de madeira e ao maior rendimento gravimétrico em carvão vegetal obtido por esse material.

Já em relação aos valores encontrados para massa de lignina total por hectare/ano, nota-se que os menores valores foram obtidos nos espaçamentos 3,0 x 0,5; 3,0 x 1,0 e 3,0 x 3,0 metros. As árvores plantadas no espaçamento 3,0 x 1,5 metros apresentaram melhores resultados, o que pode ser atribuído à sua maior massa seca por hectare/ano.

Para os valores encontrados para a estimativa de energia estocada por hectare/ano, pode-se notar que o espaçamento 3,0 x 1,5 metros, em função da sua maior massa seca, apresentaram maior quantidade de energia. Neste caso, para a estimativa de energia, considera-se, ainda, que o poder calorífico superior do carvão não apresentou diferenças significativas nos diferentes espaçamentos de plantio analisados, ou seja, esse parâmetro não influenciou na quantidade de energia disponível, ficando esta somente dependente da massa de matéria seca de madeira.

\section{Conclusões}

O espaçamento de plantio não influenciou de forma considerável a qualidade do carvão vegetal produzido a partir da madeira do híbrido de Eucalyptus grandis x Eucalyptus camaldulensis.

Considerando o rendimento e a qualidade do carvão vegetal, não houve influência do espaçamento de plantio. Já quanto a massa seca por hectare/ano, massa de carbono, massa de carvão vegetal estimada por hectare/ano, massa de lignina total por hectare/ano e energia estocada por hectare e ano, o espaçamento que se destacou foi o 3,0 x 1,5 m.

\section{Referências}

ASSOCIAÇÃO BRASILEIRA DE NORMAS TÉCNICAS. NBR 8633: Carvão vegetal: determinação do poder calorífico. Rio de Janeiro, 13 p., 1983.

ASSOCIAÇÃO BRASILEIRA DE NORMAS TÉCNICAS. NBR 8112: Carvão vegetal: análise imediata. Rio de Janeiro, 8 p., 1986.

ASSOCIAÇÃO BRASILEIRA DE NORMAS TÉCNICAS. NBR 11941: Madeira, determinação da densidade básica. Rio de Janeiro, 6 p., 2003.

BOTREL, M. C. G.; TRUGILHO, P. F.; ROSADO, S. C. da S.; SILVA, R. M. da. Melhoramento genético das propriedades do carvão vegetal de Eucalyptus. Revista Árvore. Viçosa-MG, v. 31, n. 3, p. 391398, 2007.

BRITO, J. O.; BARRICHELO, L. E. G.; COUTO, H. T. Z. do; MENDES, C. J.; RESENDE, G. C. de. Estudo do comportamento de madeiras de eucalipto frente ao processo de destilação seca. Brasília: IBDF, p. 5-36 (IBDF. Boletim técnico, 8). 1984.

CHAVES, A. M. B., VALE, A.T. V., MELIDO, R. C. N., ZOCH, V.P. Características energéticas da madeira e carvão vegetal de clones de Eucalyptus spp. Enciclopédia Biosfera, Centro Científico Conhecer - Goiânia, v.9, n.17; 2013.

INDÚSTRIA BRASILEIRA DE ÁRVORES (IBÁ). Relatório Ibá 2015. Brasília, 64p. 2015.

FERREIRA, G. W. Qualidade da celulose Kraft-antraquinona de Eucalyptus dunnii plantado em cinco espaçamentos em relação ao Eucalyptus grandis e Eucalyptus saligna. Ciência Florestal, v. 7, n. 1, p. 41-63, 1997.

LATORRACA, J. V.F., ALBUQUERQUE, C. E.C. Efeito do rápido crescimento sobre as propriedades da madeira. Revista Floresta e Ambiente. v. 7, n. 1, p. 279 - 291, jan./dez. 2000.

LEITE, H. G., NOGUEIRA, G. S., MOREIRA, A. M. Efeito do espaçamento e da idade sobre variáveis de povoamentos de Pinus Taeda L. Revista Árvore, vol. 30, n.4, Viçosa, Julho/Agosto, 2006.

LIMA, E. A.; SILVA, H. D.; MAGALHÃES, W. L. E.; LAVORANTI, O. J. Caracterização individual de árvores de Eucalyptus benthamii para uso energético. Boletim de Pesquisa e Desenvolvimento da Embrapa, Colombo, n. 35, 26 p. 2007. 
MAGALHÃES, W. M.; MACEDO, R. L. G.; VENTURIN, N.; HIGASHIKAWA, E. M.; JÚNIOR, M. Y. Desempenho silvicultural de clones e espécies/procedências de Eucalyptus na região noroeste de Minas Gerais. Revista Cerne, v. 13, n. 4, p. 368-375, 2007.

NEVES, T. A., PROTÁSIO, T. de P., COUTO, A. M., TRUGILHO, P. F., SILVA, V. O., VIEIRA, C. M. M. Avaliação de clones de Eucalyptus em diferentes locais visando à produção de carvão vegetal. Pesquisa Florestal Brasileira, Colombo, v. 31, n. 68, p. 319 - 330, 2011.

NONES, D. L., BRAND, M. A., CUNHA, A. B., C. A. F., CARVALHO, A. F., WEISE, S. M. K. Determinação das propriedades energéticas da madeira e do carvão vegetal produzido a partir de Eucalyptus benthamii. Revista Floresta, Curitiba, PR, v. 45, n. 1, p. 57-64, jan./mar. 2015.

OLIVEIRA, A.C., CARNEIRO, A.C.O., VITAL, B.R., ALMEIDA, W., PEREIRA, B.L.C., CARDOSO, M.T. Parâmetros de qualidade da madeira e do carvão vegetal de Eucalyptus pellita F. Muell. Scientia Forestalis ;38(87):431-439. 2010.

PROTÁSIO, T.P, SANTANA, J.D.P., GUIMARÃES NETO, R.M., GUIMARÃES JÚNIOR, J.B., TRUGILHO, P.F., RIBEIRO, I.B. Avaliação da qualidade do carvão vegetal de Qualea parviflora. Pesquisa Florestal Brasileira ;31(68):295-307. 2011.

REIS, A. A., MELO, I.C.N.A., PROTÁSIO, T.P., TRUGILHO, P.F., CARNEIRO, A.C.O. Efeito de local e espaçamento na qualidade do carvão vegetal de um clone de Eucalyptus urophylla S. T. Blake. Revista Floresta Ambiente. vol.19 no.4 Seropédica Oct. /Dec. 2012.

ROCHA, M. F. V., COSTA, E. V. S., JESUS, M. S., VITAL, B. R., CARNEIRO, A. C. O., CARVALHO, A. M. M. Interface of different conditions of growth and cutting age in estimating dry mass, mass of carbon and energy per hectare of Eucalyptus grandis X Eucalyptus camaldulensis clones. Australian Journal of Basic and Applied Sciences, 9(23), Pages: 175-178. 2015.

SANTOS, R. C., MENDES, L. M., MORI, F. A., MENDES, R. F. Aproveitamento de resíduos da madeira de candeia (Eremanthus erythropappus) para produção de painéis cimento-madeira. Revista Cerne - v.14, n.3, 2008.

SANTOS, R. C., CARNEIRO, A. C. O., TRUGILHL, P. F., MENDES, L. M., CARVALHO, A. M. M. Análise termogravimétrica em clones de eucalipto como subsídio para a produção de carvão vegetal. Revista Cerne. vol.18 no.1 Lavras, Jan./Mar. 2012.

SÃO PAULO (Estado). Secretaria de Agricultura e Abastecimento. Resolução SAA no 10, de 11 de julho de 2003. Norma de padrões mínimos de qualidade para carvão vegetal, como base para certificação de produtos pelo Sistema de Qualidade de Produtos Agrícolas, Pecuários e Agroindustriais do Estado de São Paulo, instituído pela Lei 10.481-9. Diário Oficial do Estado de São Paulo, São Paulo, v. 113 (129). jul. 2003.
SOARES, V. C., BIANCHI, M. L., TRUGILHO, P. F., HÖFLER, J., PEREIRA, A. J. Análise das propriedades da madeira e do carvão vegetal de híbridos de eucalipto em três idades. Revista Cerne, v. $21 \mathrm{n}$. 2, p. 191-197, 2015.

SYRED, C., GRIFFITHS, A. J., SYRED, N., BEEDIE, D., JAMES, D. A clean, efficient system for producing charcoal, heat and power (CHaP). Fuel, v.85, p. 1566-1578, 2006.

TRUGILHO, P. F., VITAL, B. R., REGAZZI, A. J., GOMIDE, J. L. Aplicação da análise de correlação canônica na identificação de índices de qualidade da madeira de eucalipto para a produção de carvão vegetal. Revista Árvore; 21(2): 259 -267.1997.

TRUGILHO, P. F.; LIMA, J. T.; MORI, F. A.; LINO, A. L. Avaliação de clones de Eucalyptus para a produção de carvão vegetal. Revista Cerne, Lavras, v. 7, n. 2, p. 114-201, 2001.

TRUGILHO, P.F., SILVA, J. R. M., MORI, F. A., LIMA, J.T., MENDES, L. M., MENDES, L. F. B. Rendimentos e características do carvão vegetal em função da posição radial de amostragem em clones de Eucalyptus. Revista Cerne, Lavras, v. 11, n. 2, p. 178-186, abr./jun. 2005.

QUIRINO, W. F., VALE, A. T., ANDRADE, P. A., ABREU, V. L. S., AZEVEDO, A. C.S. Poder calorífico da madeira e de resíduos lignocelulósicas. Biomassa \& Energia, v. 1, n. 2, p. 173-182, 2004.

VALE, A.T., ABREU, V.L.S., GONÇALEZ, J. C., COSTA, A.F. Estimativa do Poder Calorífico Superior do Carvão Vegetal de madeiras de Eucalyptus grandis em função do Teor de Carbono Fixo e do Teor de Material Volátil. Revista Brasil Florestal, nº 73, 2002.

VELLA, M.M; VALENTE, O.F., VITAL, R., LELLES, J.G. Influencia da Velocidade de Carbonização da Madeira nos Rendimentos e nas Propriedades do Carvão Produzido. Viçosa, MG; IPEF, nº 41/42; p. 64-76, 1983.

VITAL, B. R. Efeito da constituição química e da densidade da madeira de clones de Eucalyptus grandis na produção de carvão vegetal. Revista Árvore, v. 10, n. 2, p. 151-160, 1986. 